\title{
Geotecnologias aplicadas no reconhecimento de padrões de uso e cobertura da terra a partir da escala da paisagem no município de Belterra, Pará
}

\author{
Geotechnologies applied in the recognition of land use and land use patterns from the \\ landscape scale in the municipality of Belterra, Pará \\ I. C. N. P. Costa ${ }^{1 *}$ J. A. J. Corrêa ${ }^{2}$ \\ ${ }^{I}$ Instituto de Ciências da Sociedade, Universidade Federal do Oeste do Pará, 68040-070, Santarém-Pará, Brasil \\ ${ }^{2}$ Programa de Pós-graduação Doutorado em Sociedade, Natureza e Desenvolvimento, Universidade Federal do \\ Oeste do Pará, 68040-050, Santarém-Pará, Brasil
}

*izaura.pereira@ufopa.edu.br

(Recebido em 11 de maio de 2018; aceito em 29 de novembro de 2018)

\begin{abstract}
Os usos de técnicas de análise espacial, as chamadas geotecnologias, vêm contribuindo significativamente para o monitoramento, mapeamento e fiscalização das mudanças ocorridas na superfície terrestre. Entre as diversas possibilidades de uso dessas técnicas, destacam-se aquelas voltadas à análise e interpretação da paisagem e sua dinâmica, fornecendo importantes elementos à compreensão da realidade socioespacial no qual está inserida e, para, além disso, como tais processos, sobretudo antrópicos, interagem com o ambiente natural, formando padrões específicos de uso da terra. Nesse contexto, o presente trabalho tem por objetivo central analisar o emprego de geotecnologias no reconhecimento de padrões de uso e ocupação da terra a partir da escala da paisagem em uma área situada no município de Belterra, estado do Pará. Para tanto, emprega-se de forma integrada técnicas de processamento digital de imagem, com dados cartográficos e trabalho de campo. O produto gerado, a partir de uma cena Landsat TM-5, das bandas 5, 4 e 3, consistiu num mapa dos diferentes tipos de uso e cobertura da terra, os quais foram organizados em dois grandes grupos: unidades de paisagem natural e unidades de paisagem antropizadas. O que permitiu observar a distribuição espacial e a área ocupada pelas diferentes unidades detectadas, bem como avaliar a dinâmica espacial de produção e modificação da paisagem. Como suporte à análise espacial, o uso das técnicas empregadas mostrou-se de grande aplicabilidade na delimitação e caracterização de unidades de paisagem, consideradas atualmente importantes categorias de análise espacial no âmbito do planejamento e da gestão territorial.
\end{abstract}

Palavras-chave: Métrica, Landsat, Antropizada, Ambiente Natural, Monitoramento.

The uses of spatial analysis techniques, the so-called geotechnologies, have contributed significantly to the monitoring, mapping and monitoring of changes occurring on the Earth's surface. Among the various possibilities of using these techniques, we highlight those focused on the analysis and interpretation of the landscape and its dynamics, providing important elements to the understanding of the socio-spatial reality in which it is inserted and, in addition, how such processes, especially anthropic, interact with the natural environment, forming specific patterns of land use. In this context, the main objective of this study is to analyze the use of geotechnologies in the recognition of patterns of land use and occupation from the landscape scale in an area located in the municipality of Belterra, in the state of Pará. in an integrated way digital image processing techniques, with cartographic data and field work. The product generated from a Landsat TM-5 scene of bands 5, 4 and 3 consisted of a map of the different types of land use and cover, which were organized into two large groups: natural landscape units and units of anthropized landscape. This allowed to observe the spatial distribution and the area occupied by the different units detected, as well as to evaluate the spatial dynamics of production and landscape modification. As a support for spatial analysis, the use of the techniques used has shown to be of great applicability in the delimitation and characterization of landscape units, currently considered important categories of spatial analysis in the scope of planning and territorial management.

Keywords: Metric, Landsat, Anthropized, Natural Environment, Monitoring. 


\section{INTRODUÇÃO}

O uso de técnicas de sensoriamento remoto e geoprocessamento vêm contribuindo significativamente para o monitoramento, mapeamento e fiscalização das mudanças ocorridas na superfície terrestre. Atualmente, constituem o melhor instrumento aplicável ao planejamento e a gestão ambiental.

Entre as diversas possibilidades de uso dessas técnicas destacam-se aqueles voltados à análise e interpretação da dinâmica da paisagem, o qual se observa uma gama variada de pesquisas, que realizam a análise da estrutura da paisagem a partir de métodos de quantificação espacial, visando à compreensão de processos que levam a modificação da paisagem. Watrin e Venturieri (2005) [1] aplicaram as técnicas de mensuração da paisagem com o objetivo de caracterizar a cobertura vegetal e o uso da terra em projetos de assentamentos na região sudeste do Estado do Pará, Lima e Rocha (2011) [2] através de técnicas de sensoriamento remoto e métricas da paisagem analisaram a fragmentação florestal no município de Juiz de Fora (MG), sendo exemplos de aplicabilidade das geotecnologias na análise ambiental.

A análise da dinâmica da paisagem fornece importantes elementos à compreensão da realidade socioespacial da área investigada, pois permite observar através das formas criadas ou modificadas a evolução temporal dos processos que conformam essa realidade e, para, além disso, como tais processos, sobretudo antrópicos, interagem com o ambiente natural. Segundo Sauer citado por Christofoletti (1999) [3], isso é possível porque o conteúdo da paisagem é constituído pela combinação de todos os elementos naturais, disponíveis em um lugar, com as obras humanas. O que ocorre de forma interdependente entre os diversos constituintes e não pela simples adição de um sobre o outro, evocando, assim o papel do tempo nesse contexto.

Todo e qualquer processo ecossistêmico necessita ser investigado no âmbito do contexto sócio-espacial o qual faz parte, pois os processos sociais intrínsecos a esse contexto podem interferir significativamente nessa dinâmica de maneira negativa e irreversível. Considerando que todos os elementos da natureza estão interligados, formando um grande sistema, qualquer alteração em um desses elementos por menor que seja, vai causar algum tipo de perturbação, assim, os dados gerados precisam transcender aspectos estritamente ambientais e incorporar dimensões antrópicas de forma integrada e inter-relacionada. Utilizar a paisagem enquanto unidade de análise possibilita, dessa forma, o alcance de tal proposição, por admitir que a paisagem em escala macro é formada por um mosaico complexo, que integra unidades de paisagens naturais e paisagens antropizadas.

A delimitação dessas unidades de forma a representar de fato a paisagem a ser analisada precisa levar em consideração alguns pressupostos relacionados à escala, a resolução das imagens usadas, a precisão e a agregação dos objetos observados na superfície terrestre [4]. Elementos esses que influenciam sobremaneira na representação das estruturas da paisagem, bem como no cálculo de suas medidas. Enquanto categoria de análise espacial, a Unidade de Paisagem (UP) pode ser compreendida como um esforço para gerar dados e informações representativas e com maior riqueza de detalhes da área de interesse e corresponde a uma unidade que pode ser individualizada em relação a um determinado atributo, porém sendo homogênea em si mesma [5], e que compõe o mosaico da paisagem. Considerando que a paisagem é formada por um mosaico de unidades, a caracterização e identificação das UP consistem na análise, no mapeamento cartográfico e na quantificação da área ocupada em relação ao todo adjacente, além da compreensão da estrutura, da composição e dos processos intrínsecos a unidade em estudo [6] .

De acordo com Aragão et al. (2003) [7], em se tratando de Amazônia, a ausência de dados é um fator limitante a compreensão de vários processos ecológicos que ocorrem na região. Nesse sentido, os avanços na área de geotecnologia e a disponibilidade de imagens orbitais e softwares de processamento digital de imagens de satélite de forma gratuita, vem tornando o uso das métricas na análise da estrutura da paisagem cada vez mais frequente.

No estudo da paisagem o uso de geotecnologias se tornou um instrumento necessário, já que a perspectiva informacional que as mesmas fornecem, ultrapassa a simples descrição e o reconhecimento dos alvos na superfície terrestre. Entretanto, o sucesso no uso das mesmas depende também do conhecimento da área investigada. O uso do sensoriamento remoto e do Geoprocessamento não substitui o trabalho de campo, ao contrário, ambos se complementam. Porém, em situações em que a ida a campo não for possível, os produtos gerados, geralmente mapas temáticos, podem ser usados para um conhecimento prévio do lugar, bem como para a quantificação de tendências e padrões espaciais ao longo do tempo. 
Diante disso, o presente trabalho analisa o emprego de geotecnologias no reconhecimento de padrões de uso e ocupação da terra a partir da escala da paisagem em uma área situada no município de Belterra, estado do Pará.

\section{MATERIAL E MÉTODOS}

\section{1 Área de estudo}

A área investigada no presente trabalho possui aproximadamente $455,7 \mathrm{~km}^{2} \mathrm{e}$ situa-se entre as

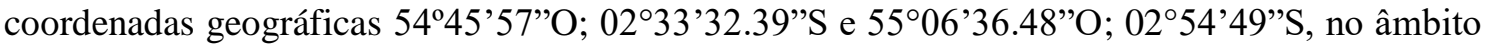
do município de Belterra, porção oeste do Estado do Pará (Figura 1).

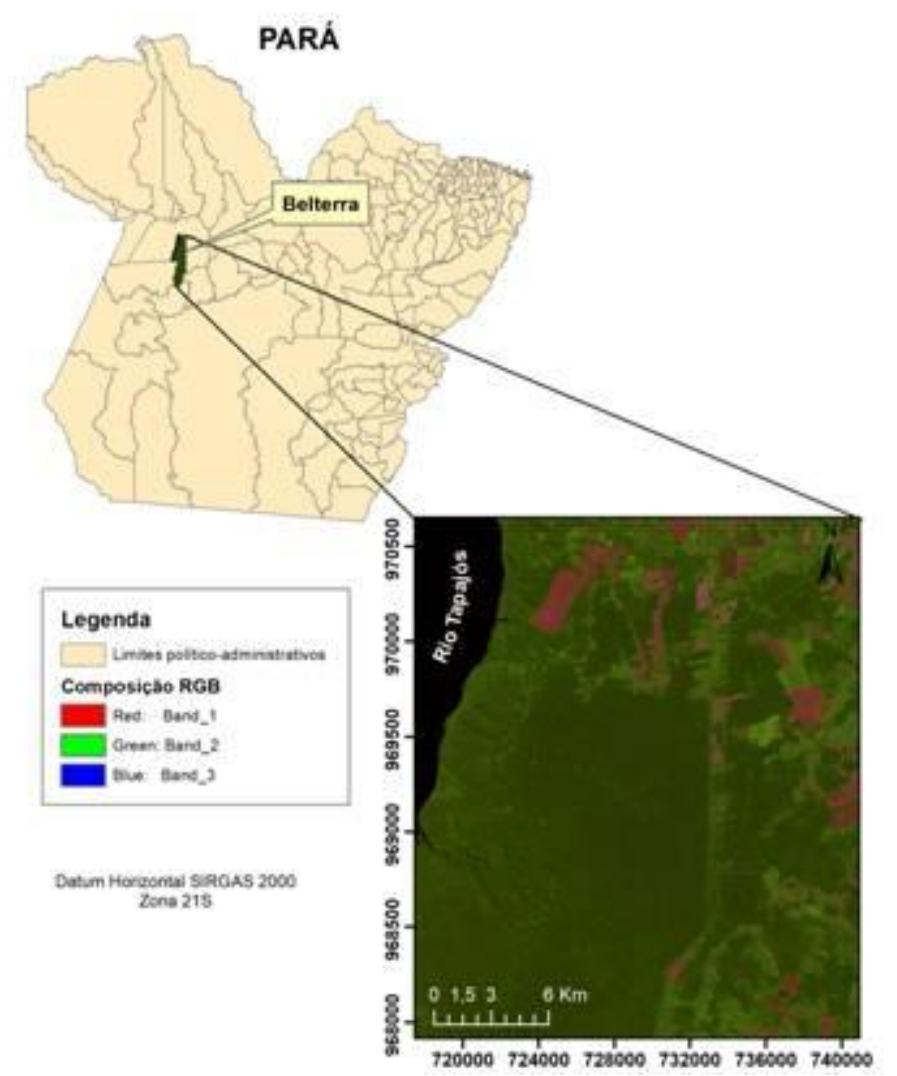

Figura 1: Localização da área de estudo no município de Belterra, oeste do Pará. Fonte: Autores, 2018.

A escolha dessa realidade empírica levou em consideração o contexto socioeconômico e o potencial ecológico [8] existente na mesma, conforme verificado durante um primeiro levantamento de campo, em nível de reconhecimento, realizado em outubro de 2010, que permitiu observar o enorme contraste na paisagem com a presença de parcelas agricultáveis de soja, sendo que o local abriga também um potencial natural de grande importância ecológica com a presença de ecossistemas de transição entre a floresta densa e o cerrado.

Nesse local, a dinâmica das águas produz anualmente duas paisagens bem distintas, diretamente relacionadas com as duas estações climáticas características da região amazônica: a estação seca (julho/dezembro) e a estação chuvosa (janeiro/junho).

\subsection{Geração do Mapa de Unidades de Paisagem}

Com base no Mapa Fitoecológico do Projeto Radar da Amazônia (RADAM) [9] da Folha SA. 21- Santarém identificou-se nove tipologias florestais, as quais foram agrupadas em duas grandes categorias:

a) Paisagem Natural - Floresta Tropical Aberta, com áreas sedimentares, relevo aplainado, alto platô dissecado com árvores emergentes; Floresta Tropical Aberta, com áreas sedimentares, 
relevo ondulado e baixo platô dissecado com árvores emergentes; Zona de Tensão Ecológica (Floresta/Cerrado); Floresta Secundária.

b) Paisagem Antropizada - Uso urbano; Pasto; Desmatamento; Uso agrícola e Solo exposto.

Uma campanha de campo foi realizada para identificação das principais unidades de paisagens presentes na área de estudo, as quais podem ser visualizadas na Figura 2.

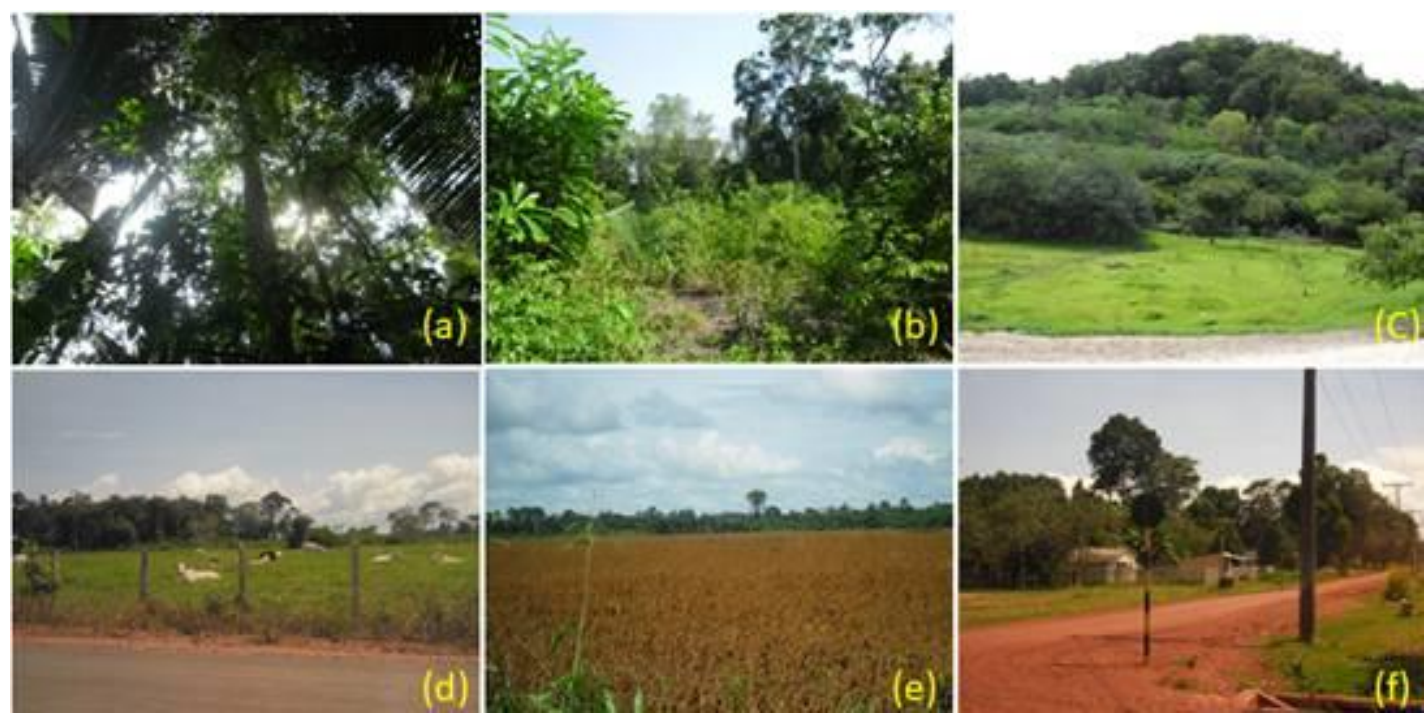

Figura 2: Principais tipos de uso e cobertura do solo na área de estudo a) Floresta de Alto Platô, $b$ ) Trecho de floresta secundária, c) Zona de transição ecológica, d) Pasto, e) Uso agrícola, f) Uso urbano. Fonte: Autores, 2018.

De posse dessa informação utilizou-se uma cena do satélite Landsat TM 5 da órbita/ponto 227/62, ano de 2010, para a geração do mapa de Unidades de Paisagem (UP), utilizando, para tanto, a composição de bandas 5, 4 e 3 para a melhor discriminação dessas classes.

\subsection{Processamento e padronização dos dados cartográficos}

Nesta etapa foi realizado o processamento e a padronização dos dados cartográficos para a mesma escala, projeção e datum horizontal. O que foi realizado através do software ArcGis (Geographic Information System) versão 10.0 (2010). Nesta etapa também foi utilizado o software SPRING (Sistema de Processamento de Informações Georreferenciadas) versão 5.2 (2013), gratuitamente distribuído pelo INPE (Instituto Nacional de Pesquisas Espaciais).

a) Dados de Vegetação: processamento e análise

O mapa fitoecológico dos quadrantes Santarém (SA-21-Z-B) e Aveiro (SA-21-Z-D), digitalizados em formato pdf., foram convertidos para o formato tiff (raster) e em seguida adicionados ao ArcGis. Logo após, procedeu-se ao georreferenciamento da imagem para a projeção Universal Transversa de Mercator (UTM) e datum horizontal SIRGAS (Sistema de Referência Geocêntrico para as Américas) 2000. Utilizou-se 5 pontos de referência espacial da própria imagem, após convertidos de coordenadas geográficas (Latitude/Longitude) para coordenadas planas.

A partir desse mapa foi possível observar a distribuição espacial das unidades de cobertura florestal presente na área de estudo, servindo, assim como referência também ao processo de classificação digital, a ser realizado adiante.

b) Dados de Altimetria: processamento e análise

Os dados de altimetria foram extraídos da imagem SRTM folha SA.21-Z-B, para visualização da topografia do terreno e posterior integração com os dados de vegetação. 
A imagem foi exportada para o banco de dados do SPRING para a construção de um Modelo Digital do Terreno (MDT), e nesse processo definiu-se o valor do pixel em 30m. Em seguida a imagem foi fatiada em seis intervalos de 50 metros de elevação no intervalo entre 0 a 250 metros, gerando um mapa temático matricial de altimetria.

\subsubsection{Processamento digital}

O processamento da imagem Landsat foi realizado no software SPRING. Já a edição final dos produtos temáticos, obtidos a partir do processamento, foi realizada no ArcGis.

Nesta fase as três bandas selecionadas foram registradas e, posteriormente, realizado a correção radiométrica correspondentes à conversão dos números digitais (ND) para valores de reflectância aparente, conforme Ponzoni e Shimanbukuro (2007) [10].

A calibração radiométrica consiste no cômputo da radiação espectral em cada banda $\left(\mathrm{L}_{\lambda \mathrm{i}}\right)$, em que o número digital (ND) de cada pixel da imagem é convertido em radiância espectral monocromática, segundo a equação proposta por Markham e Baker (1987)[11] (Equação 1):

$$
L_{\lambda, i}=a_{i}+\frac{b_{i}-a_{i}}{255} N D \quad \text { Equação (1) }
$$

Em que a e b são as radiâncias espectrais mínimas e máximas $\left(\mathrm{Wm}^{-2} \mathrm{sr}^{-1} \mu \mathrm{m}^{-1}\right)$, ND é a intensidade do pixel (número inteiro compreendido entre 0 e 225) e i corresponde as bandas (1, $2, \ldots$ e 7 ) do satélite Landsat 5 TM.

A reflectância pode ser definida como sendo a razão entre o fluxo de radiação refletida e o fluxo de radiação incidente que é obtida segundo a equação de Allen et al., (2002) [12] (Equação 2):

$$
\rho_{\lambda, i=\frac{\pi \cdot L_{\lambda, i}}{\mathrm{~K}_{\lambda, i} \cos \mathrm{Z} \cdot d_{r}}} \quad \text { Equação (2) }
$$

Onde $\mathrm{L}_{\lambda \mathrm{i}}$ é a radiância espectral de cada banda, $\mathrm{K}_{\lambda \mathrm{i}}$ é a irradiância solar espectral de cada banda no topo da atmosfera $\left(\mathrm{Wm}^{-2} \mu \mathrm{m}^{-1}\right)$, $\mathrm{Z}$ é o ângulo zenital solar e $\mathrm{d}_{\mathrm{r}}$ é o quadrado da razão entre a distância média Terra-Sol ( $\mathrm{r}_{0}$ ) e a distância Terra-Sol (r) em dado dia do ano (DSA).

Visando reduzir os efeitos da atmosfera sobre os valores de reflectância procedeu-se a correção atmosférica da imagem, o que foi realizado a partir do método DOS (Dark Object Subtration), criado por Chavez (1989) [13], com o auxílio da planilha eletrônica desenvolvida por Gürtler et al. (2005) [14]. Por fim, após valores corrigidos dos pixels procedeu-se a classificação supervisionada Battacharya por regiões, algoritmo implementado no software SPRING.

\subsection{Métrica de Unidade de Paisagem}

Após o mapeamento das unidades de paisagem, realizou-se a quantificação e a análise da área ocupada por cada uma ao nível da mancha. Segundo Lang e Blaschke (2009) [4], a área é a medida da estrutura da paisagem mais difundida entre as métricas existentes.

Através da geração de um arquivo vetorial da imagem matriz classificada em etapa anterior, obteve-se a área total de cada classe em metros quadrados $\left(\mathrm{m}^{2}\right)$, e que posteriormente foi convertida para hectares (ha). Ao criar o plano vetorial através da função "Medidas de Classes" presente na aba Temático do menu principal do software em questão, foi possível obter, de modo interno ao sistema, os valores de área para cada mancha identificada.

No plano vetorial, a área de um polígono é mensurada pela subdivisão de conteúdo do mesmo em formas geométricas básicas. O cálculo é realizado a partir da fórmula descrita abaixo (Equação $3)$ :

$$
\text { Área }=0,5 \times \sum\left(X_{i+1}-X_{i}\right) \cdot\left(Y_{i+1}+Y_{i}\right)
$$

Onde: x e y-coordenadas do $i$-ésimo ponto de apoio do polígono.

A medida de área é considerada uma das mais importantes entre as medidas disponíveis, pois além de ser base para a construção de outras métricas, possibilita a análise quali-quantitativa da relação entre a redução e o aumento de classes específicas (relativas ao uso e cobertura da terra), em um determinado recorte espaço-temporal. 
A partir dessa métrica calculou-se o percentual de área ocupada por cada UP na área de estudo.

\section{RESULTADOS E DISCUSSÃO}

\subsection{Mapas Fitoecológico e Altimétrico da área de estudo}

No mapa fitoecológico da área de estudo (Figura 3a) pode-se observar seis classes de uso e cobertura da terra: água, floresta densa de baixo platô, floresta densa de alto platô, zona de transição ecológica, vegetação secundária sem palmeiras e áreas com agropecuária. Já o mapa altimétrico (Figura 3b) apresenta cinco classes de elevações variando de 50 a 200 metros.
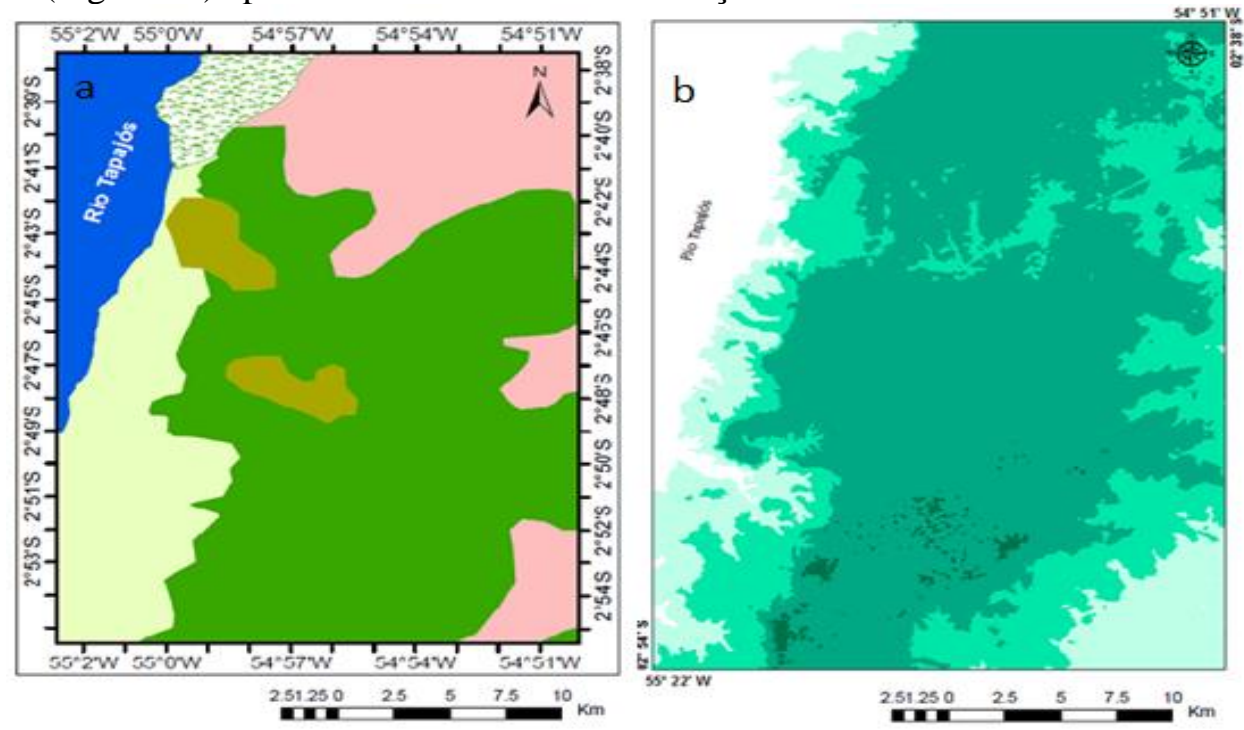

Legenda

C Massa dágua

Floresta

Floresta densa de baixo platō (relevo aplainado)

Floresta densa de alto paltô

Áreas de Tensão Ecológica

EiPe Zona de contato (Floresta/Cerrado)

Áreas Antrópicas

Agropecuária

Vegetação secundária sem palmeiras

Figura 3: Mapas fitoecológico (a) e altimétrico (b) da área de estudo no município de Belterra, oeste do Pará. Fonte: Autores, 2018.

Na Figura 4 pode-se visualizar a representação percentual das demais classes altimétricas. Considerando as classes de altimetria, observa-se que a mais representativa é a de 150-200, cobrindo aproximadamente 59\% da área total, seguida pela classe de 100-150 que ocupa uma área de aproximadamente $25 \%$. 


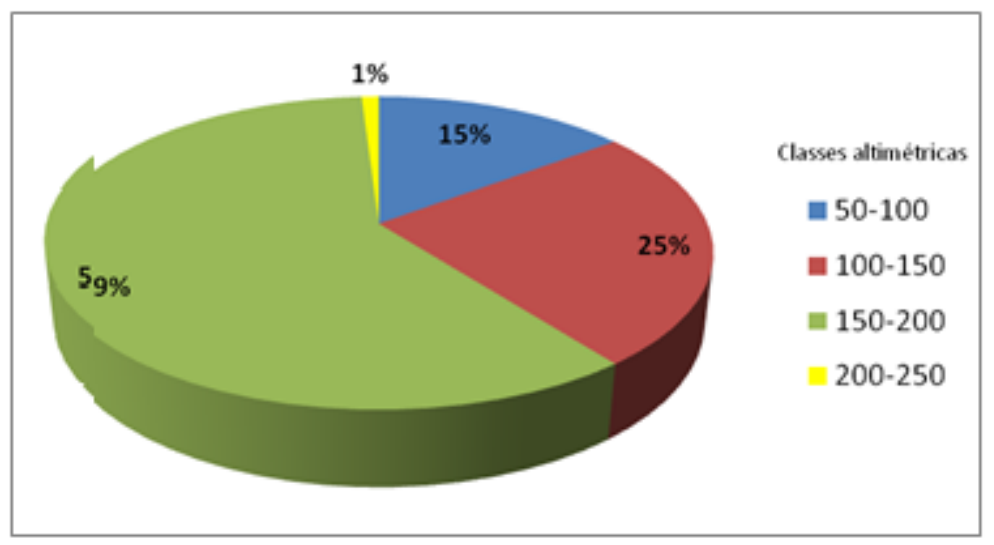

Figura 4: Área relativa das classes altimétricas na área de estudo no município de Belterra, oeste do Pará. Fonte: Autores, 2018.

Observou-se que as classes de cobertura florestal estão bem definidas e localizadas em cotas altimétricas específicas, estando as florestas de baixo platô e a zona de transição situadas entre as cotas 51 a 150 metros e a floresta de alto platô na faixa acima de 150 metros.

\subsection{Mapeamento das Unidades de Paisagem}

Na Figura 5 pode ser observar a distribuição e a representatividade espacial das classes identificadas, distribuídas em dois grandes grupos. Ressalta-se que para os objetivos propostos as unidades foram identificadas a partir das diferentes classes de uso e cobertura da terra, assim, seus limites não se restringem aos grandes agregados geomorfológicos, classicamente, empregados no processo de individualização das unidades de paisagem.

No que tange ao grupo com cobertura vegetal foram consideradas duas tipologias de unidades de paisagem: Unidades Naturais e Unidades Alteradas. A primeira tipologia incluiu as seguintes classes: Floresta de alto platô (Fap), Floresta de baixo platô (Fbp) e Tensão Ecológica (TEc). Já a segunda as classes Vegetação Secundária (VegSec) e Vegetação secundária sem palmeira (Vssp). Quanto ao grupo sem cobertura vegetal, foi atribuída apenas uma tipologia de unidade de paisagem, denominada Unidade Antropizada. Esta unidade foi composta por quatro classes de uso do solo: pasto, solo exposto, uso urbano e uso agrícola.

As classes de florestas naturais distribuem-se na área, seguindo a variação do relevo, conforme observado no mapa altimétrico. A grande diferença notada foi em relação à classe Tensão Ecológica, quando comparado ao mapa fitoecológico do projeto RADAM (Radar da Amazônia), pois na área de estudo, diferentemente do que é apresentado no mapa citado, as áreas de tensão ecológica, (que neste caso refere-se ao encontro das tipologias floresta densa com o cerrado) ocorrem paralelas às margens do rio, no sentido norte-sul. Não constituem áreas muito extensas e aparecem de modo descontínuo ao longo do Rio Tapajós, conforme pode ser observado no mapa de unidades de paisagem.

Entre as unidades antropizadas, destaca-se a classe "Uso agrícola" cujas manchas ocupam grande parte da área investigada. Interessa destacar que a localização das manchas pertencentes a esta classe, situam-se as proximidades do núcleo urbano do município de Belterra.

A classe Vegetação Secundária aparece bem distribuída na área. No que tange à classe Floresta Secundária sem Palmeira cumpre destacar que apesar da mesma não ter sido identificada em campo, ela foi incorporada ao mapa final no processamento digital, por aparecer tanto no Mapa Fitoecológico do Projeto RADAM (1976) [8], quanto no mapa de Ambientes Fitoecológicos do Plano de Manejo da Flona Tapajós (2004) [15].

No caso do uso "Desmatamento" observado durante a coleta de campo, o mesmo não foi identificado pelas técnicas de sensoriamento empregadas. Isto pode ser atribuído ao tamanho da área, em relação à resolução espacial da imagem orbital empregada $\left(900 \mathrm{~m}^{2}\right)$, e a característica do processo de desmatamento usado, com a não retirada total da matéria orgânica, cuja resposta no sensor aparece como área coberta com vegetação. Desse modo, tal classe foi incorporada à classe vegetação secundária. 


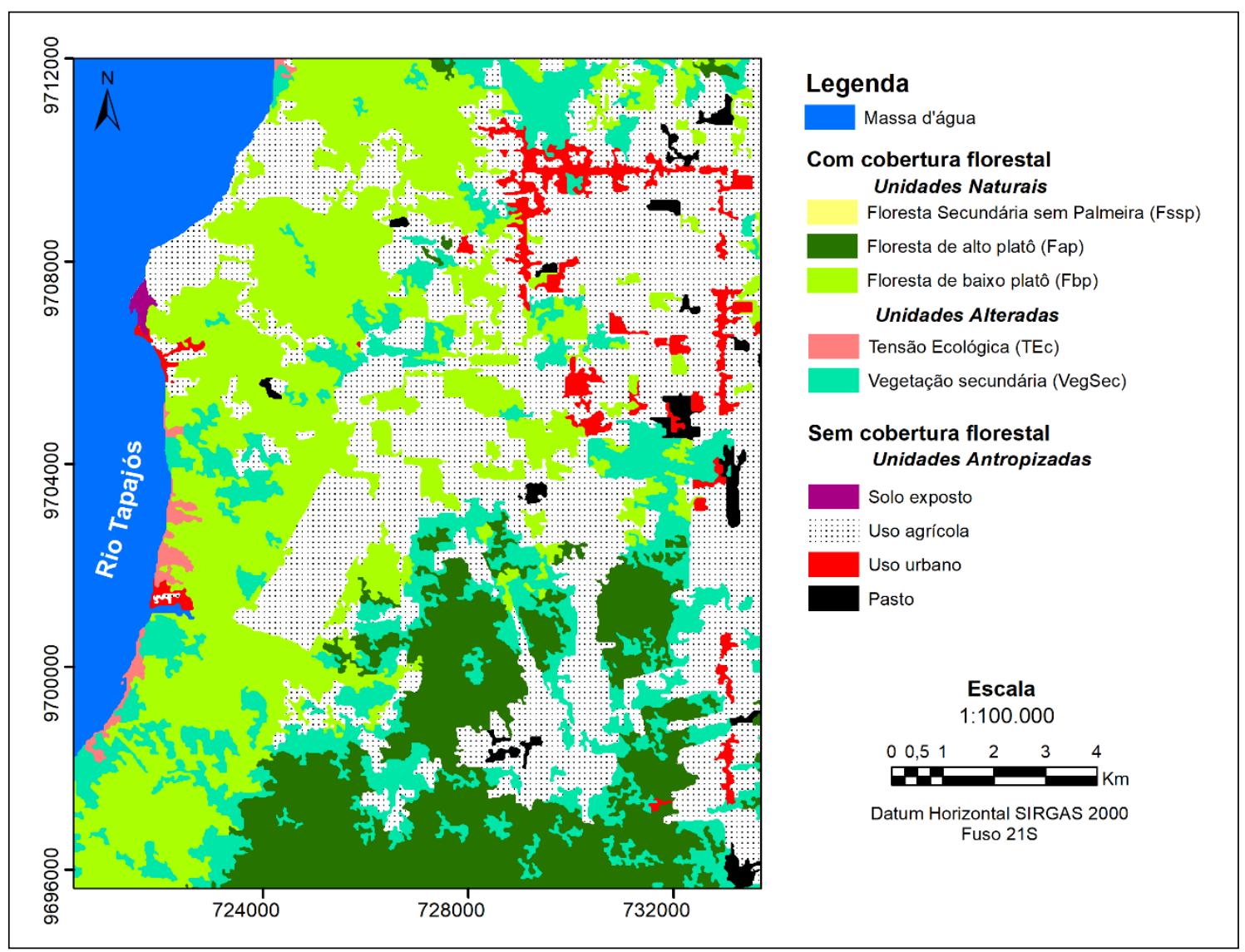

Figura 5. Mapa de Unidade de Paisagem na área de estudo no município de Belterra, oeste do Pará. Fonte: Autores, 2018.

Ressalta-se que o mapa da Figura 5 gerado considerou como parâmetro de análise a vegetação, por entender que esta representa a síntese da interação entre os geofatores, o que se apresenta como possibilidade metodológica na confecção de mapas de unidades de paisagem, mas não a única. No geral, os mapas relacionam o modelado do terreno a partir da distribuição das cotas altimétricas na identificação das unidades. Porém, dependendo da escala de análise, tal critério pode ser desconsiderado.

\subsection{Métrica das Unidades de Paisagem}

Conforme a Tabela 1 o grupo com cobertura vegetal está em maior proporção na área com $60,46 \%$, sendo a unidades naturais com a maior área com um total de 21.769,39 ha. Os resultados gerados permitem observar que, no âmbito das unidades de paisagem antropizadas, o uso agrícola representa quase $25 \%$ do total, superando até mesmo o percentual de área ocupada pela unidade de paisagem natural Floresta de baixo platô, com 19,62\%. O uso urbano corresponde a menos de $2 \%$, demonstrando que o núcleo urbano do município de Belterra possui baixa evolução urbana. A população total de Belterra, segundo o Censo Demográfico de 2010 corresponde a 16.324 habitantes, dos quais $6.853(41,98 \%)$ residem na área urbana e $9.471(58,01 \%)$ na área rural. Desse modo, caracteriza-se como um município predominantemente rural [16].

$\mathrm{Na}$ atualidade, no que diz respeito ao setor econômico, merece destaque a agricultura mecanizada de grãos, sobretudo da soja, cujo crescimento em termos de área plantada (hectares) ao longo dos anos vem ocorrendo de forma considerável. Tal atividade é considerada a principal forçante do desmatamento no município no dias atuais, juntamente com o setor agropecuário. Além da derrubada da floresta, a soja gera impactos ambientais indiretos como erosão do solo e a contaminação ambiental por uso de herbicidas, inseticidas e fungicidas químicos de efeitos colaterais sobre as florestas adjacentes e ao sistema hídrico e biológico [17]. Além desses, cumpre destacar ainda os impactos na sociedade local, tais como o aumento dos conflitos no campo, expulsão do pequeno produtor de suas terras, êxodo rural, redução e aumento do preço dos gêneros alimentícios, entre outros [18]. 
No caso da unidade Floresta de alto platô, a mesma ocupa a maior parte da área investigada representando $27,21 \%(12.550,16 \mathrm{ha})$ da área total estudada. A maior parte desta unidade localizase no âmbito da Floresta Nacional do Tapajós, porém chama-se atenção às áreas adjacentes a esta unidade de conservação federal, que podem vim a reduzir seus valores ao longo dos próximos anos em virtude da dinâmica econômica desse entorno.

Tabela 1: Área ocupada pelas UPs em 2010 identificadas na área de estudo no município de Belterra, oeste do Pará.

\begin{tabular}{ccccc}
\hline Grupo & Unidades & Classes & Área (ha) & \% \\
\hline \multirow{3}{*}{$\begin{array}{c}\text { Com cobertura } \\
\text { florestal }\end{array}$} & Naturais & Fap & 12550,16 & 27,21 \\
& & Fbp & 9047,79 & 19,62 \\
& \multirow{3}{*}{ Alteradas } & TEC & 171,44 & 0,37 \\
& & Fssp & 379,99 & 0,82 \\
& & VegSec & 5734,78 & 12,44 \\
& & Pasto & 644 & 1,40 \\
Sem cobertura & Antropizadas & Uso urbano & 884,49 & 1,92 \\
florestal & & Uso agrícola & 11189,85 & 24,26 \\
& & Solo exposto & 25,97 & 0,06 \\
& \multirow{2}{*}{ Água } & Massa d'água & 5487,74 & 11,90 \\
\hline & Total & & $\mathbf{4 6 1 1 6 , 2 1}$ & $\mathbf{1 0 0}$ \\
\hline \multicolumn{2}{c}{ Fonte: Autores, 2018. }
\end{tabular}

Contudo, tais medidas muito mais que um simples cálculo de área, possibilita, agregadas com outros dados, avaliar a dinâmica espacial de produção e modificação da paisagem em qualquer ponto da superfície terrestre. Dados quantitativos são muitos úteis para a realização de análises comparativas entre variáveis, tanto no mesmo período, quanto em períodos diferentes.

\section{CONCLUSÃO}

Enquanto escala espacial, as unidades de paisagem constituem um importante aporte na análise de questões socioambientais, no que tange à dinâmica da paisagem e suas implicações nos processos biofísicos.

Neste trabalho as unidades de paisagem foram identificadas a partir dos diferentes tipos de uso e cobertura da terra, partindo da compreensão que tais usos e coberturas da terra representam a síntese de múltiplas interações, sejam elas ambientais ou sociais. Assim, foi possível discriminar unidades naturais e unidades antropizadas na área investigada.

Como suporte à análise espacial, o uso das técnicas aqui empregadas mostrou-se de grande aplicabilidade, sobretudo no concernente a delimitação e caracterização de unidades de paisagem, consideradas atualmente importantes categorias de análise espacial no âmbito do planejamento e da gestão territorial. Considerou-se, desse modo, satisfatório os resultados obtidos, embora deva ser ressaltado que tais técnicas também apresentam limitações.

Em se tratando de Amazônia, o emprego das geotecnologias vem ampliando o leque de conhecimento sobre região, onde processos antrópicos voltados à exploração dos recursos naturais e a derrubada da floresta, alteram drasticamente a paisagem regional, criando mosaicos cada vez mais fragmentados e diversificados em detrimento da paisagem original, como pôde ser constatado na área de estudo.

Assim, cumpre destacar que a categorização do espaço geográfico em unidades de paisagem, conforme mostrado no mapa de unidades de paisagem, pode ser usado como referência para outros trabalhos ao permitir a visualização da organização espacial do lugar, além de outras condicionantes, como o grau de retalhamento e a predominância de uma unidade em relação à outra, por exemplo. 


\section{AGRADECIMENTOS}

Os autores agradecem ao CNPq pelo apoio financeiro ao desenvolvimento dessa pesquisa.

\section{REFERÊNCIAS BIBLIOGRÁFICAS}

1. Watrin OS, Santos JR, Filho MV. Análise da dinâmica na paisagem do nordeste paraense através de técnicas de geoprocessamento. Anais VIII Simpósio Brasileiro de Sensoriamento Remoto - SBSR, 1996 Abr 14-19; Salvador, BA, Brasil, p. 427-433.

2. Lima RNS, Rocha CHB. Técnicas de sensoriamento remoto e métricas de ecologia da paisagem aplicadas na análise da fragmentação florestal no município de Juiz de Fora - MG em 1987 e 2008. Anai XV Simpósio Brasileiro de Sensoriamento Remoto - SBSR, 2011 Abr 30 - Mai 5; Curitiba, PR, Brasil, p. 2067-2074.

3. Christofoletti A. Modelagem de sistemas ambientais. São Paulo: Edgar Blucher; 1999.

4. Lang S, Blaschke T. Análise da paisagem com SIG. São Paulo: Oficina de Textos; 2009.

5. Zonneveld IS. The land unit- a fundamental concept in landscape ecology, an its applications. Landscape Ecol. 1989;3(2):67-86.

6. Rodriguez JMM, Silva EV, Cavalcanti APB. Geoecologia das paisagens: uma visão geossistêmica da análise ambiental. Fortaleza: UFC; 2007.

7. Aragão LEOC, Shimabukuro YE, Espírito-Santo FDB. Integração de dados geo-espaciais para definição de unidades de paisagem na região do Tapajós: aquisição de parâmetros ecológicos no campo para modelagem da produtividade florestal em escala regional. Anais XI Simpósio Brasileiro de Sensoriamento Remoto - SBSR, 2003 Abr 5-10; Belo Horizonte, MG, Brasil, p. 1263 - 1270.

8. Folhes RT, Magalhães CO, Marianelli GS. Mapeamento participativo socioambiental: a experiência da Área de Proteção Ambiental Aramanaí, no município de Belterra, Pará. Anais IV Semana de Informática, II Semana de Geotecnologias, I Escola de Software Livre, 2007; Santarém, PA, Brasil, p. 181-182.

9. Projeto Radam: Folha SA-21 - Santarém. Rio de Janeiro: Ministério de Minas e Energia, Departamento de Produção Mineral (DNPM); 1976. v. 1 (Levantamentos de recursos naturais, 10).

10. Ponzoni FJ, Shimabukubo YE. Sensoriamento Remoto no estudo da vegetação. São José dos Campos: Parêntese; 2007.

11. Markham BL, Barker JL. Thematic Mapper band pass solar exoatmospherical irradiances. Internat J Remote Sensing. 1987;8(3):517-523.

12. Allen RG, Tasumi M, Trezza R. SEBAL (Surface Energy Balance Algorithms for Land) - Advanced Training and Users Manual - Idaho Implementation, 2002, version 1.0.

13. Chavez Jr PS. An improved dark-object subtraction technique for atmospheric scattering correction for multispectral data. Remote Sensing Environm. 1988;24:459-479.

14. Gürtler S, Epiphanio JCN, Luiz AJB, Formaggio AR. Planilha eletrônica para o cálculo da reflectância em imagens TM e ETM+ Landsat. Rev Bras Cartogr. 2005;57(2):162-167.

15. Plano de Manejo- Floresta Nacional do Tapajós. Brasília, DF: MMA/IBAMA; 2004. v. 1.

16. Censo Demográfico, 2010. Características da população e dos domicílios: resultados do universo. Rio de Janeiro: IBGE, 2011. Acompanha 1 CD-ROM. Disponível em: http://www.ibge.gov.br/home/estatistica/ populacao/censo2010/caracteristicas_da_populacao/resultados_do_universo.pdf. Acesso em: mar. 2013.

17. Fearnside PM. Soybean cultivation as a threat to the environment in Brazil. Environm Conserv. 2001;28(1):23-38.

18. Cohenca D. A expansão da fronteira agrícola e sua relação com o desmatamento detectado em imagens Landsat TM e ETM+ na região norte da BR-163, Pará entre os anos de 1999 e 2004. 2005. [Monografia]: Lavras (MG) - Universidade Federal de Lavras, 2005. 